\title{
Sustainable natural adsorbents for heavy metal removal from wastewater: lead sorption on pine bark (Pinus radiata D.Don)
}

\author{
Gonzalo Montes-Atenas ${ }^{a *}$ and Sven L. M. Schroeder ${ }^{b, c, d}$
}

Aqueous $\mathrm{Pb}$ (II) adsorption on pine bark (Pinus Radiata D.Don), an inexpensive and sustainable natural sorbent material, has been evaluated and the mechanism of metal retention characterized by scanning electron microscopy (SEM), diffuse reflectance infrared Fourier transform spectroscopy (DRIFTS) and X-ray photoelectron spectroscopy (XPS). Bark pulp densities $>1.5 \mathrm{~g} \mathrm{I}^{-1}$ achieve near $100 \% \mathrm{~Pb}$ (II) removal from aqueous solutions containing $100 \mathrm{mg} \mathrm{I}^{-1} \mathrm{~Pb}(\mathrm{II})$. Adsorption rates increased with pulp density, although adsorption capacity diminished at high densities because of blockage of adsorption sites. The effects of washing and sulfuric acid activation were assessed and found to be less important than in previous metal sorption studies. $\mathrm{Pb}$ (II) sorption takes place mainly at the lignocellulosic C-O groups, with adsorption at phenolic sites appearing to be most significant. $\odot 2016$ The Authors. Surface and Interface Analysis published by John Wiley \& Sons, Ltd.

Additional supporting information may be found in the online version of this article at the publisher's web site.

Keywords: wastewater; adsorption; heavy metals; lead; pine bark; biosorbents

\section{Introduction}

There is an urgent need for the development of environmentally sustainable processes for the decontamination of wastewaters and of natural water streams contaminated with heavy metals. Particularly in the mining industry the presence of mixtures of heavy metals in aqueous contaminated solutions presents real challenges even to the application of traditional water treatment methods such as precipitation and filtration of the metal hydroxides or salts. ${ }^{[1]}$

Considerable research over the last two decades has explored the use of inexpensive sustainable sorbent materials such as bark or wood chips for the removal of soluble heavy metal species from aqueous solutions. ${ }^{[2-11]}$ By using these materials residual heavy metal concentrations as low as $1 \mathrm{mg}$ per ton can be achieved, ${ }^{[12]}$ results unattainable by classic paths.

As a further contribution to this field, we have now examined the sorption of lead onto bark, which is a widely available and currently inexpensive waste material from the wood industry. Lead is highly toxic for humans yet is commonly released into the natural environment from various process and waste streams. ${ }^{[13,14]}$ Currently the main use for bark is as a combustible, with little added value. Its utilization as sorbent may open up avenues to other applications such as the concentration of the sorbed metal (elution, pyrolysis, etc) and the production of activated carbon (Guedes de Carvalho et al. 1984).

One potential problem associated with the use of bark in the removal of heavy metals is its intrinsic content of natural organic complexation agents such as tannins, which can be soluble enough to be released in significant concentrations and stabilize contaminants in solution rather than remove them (Nakajima and Baba, 2004; Karamac, 2009). A pre-treatment of bark is therefore required to remove or inactivate such complexation agents. Acid activation has been shown to increase the adsorption capacity and to eliminate soluble tannins (Osawa and Walsh, 1993). However, the activation in acid media is highly variable depending on the nature of the activating agent, its concentration and the temperature. ${ }^{[1,15]}$

Previous research has indicated that the adsorption process can be usefully performed at $\mathrm{pH}$ values under which heavy metal ions remain in solution on one hand while high bark pulp densities can be maintained on the other. ${ }^{[2,16]}$ The kinetics of adsorption under these conditions is usually parametrically presented as a function of either the pulp density or the ion concentration. The maximum adsorption capacity depends in a complex manner on the properties of both the ion solution and the substrate. In order to optimize the overall sorption process, the mechanism of sorption

\footnotetext{
* Correspondence to: G. Montes-Atenas, Minerals and Metals Characterisation and Separation $\left(M^{2} C S\right)$ Research Group, Mining Engineering Department, Faculty of Physical and Mathematical Sciences, The University of Chile, Chile. E-mail: gmontes@ing.uchile.cl
}

This is an open access article under the terms of the Creative Commons Attribution License, which permits use, distribution and reproduction in any medium, provided the original work is properly cited.

The copyright line for this article was changed on 11 April 2016 after original online publication.

a Minerals and Metals Characterisation and Separation $\left(M^{2} C S\right)$ Research Group Mining Engineering Department, Faculty of Physical and Mathematical Sciences, The University of Chile, Santiago, Chile

b School of Chemistry, The University of Manchester, Brunswick Street, Manchester M13 9PL, United Kingdom

c School of Chemical and Process Engineering, University of Leeds, Leeds LS2 9JT, United Kingdom

d Diamond Light Source Ltd., Diamond House, Harwell Science and Innovation Campus, Fermi Ave, Didcot, Oxfordshire OX11 0QX, United Kingdom 
must be identified. The aim of the present work is therefore to establish sorption kinetics curves for lead on pine bark, and to obtain information about the sorption mechanism to begin to build up a deeper understanding of the process.

\section{Materials and methods}

Pine bark obtained from the South of Chile was ground to a particle size distribution lower than $1 \mathrm{~mm}$ and washed in distilled water. The material was then chemically activated by stirring for $2 \mathrm{~h}$ in $0.2 \mathrm{~mol} / \mathrm{l}$ sulfuric acid solution at $25^{\circ} \mathrm{C}$, with a solid-liquid ratio equal to $1: 10$. Subsequently, the bark was washed with distilled water until reaching neutral $\mathrm{pH}$ and then dried in an oven at $30^{\circ} \mathrm{C}$.

Batch experiments were performed to determine the kinetics of heavy metal extraction. Aqueous solutions of high purity lead nitrate, $\mathrm{Pb}\left(\mathrm{NO}_{3}\right)_{2}$ (Merck, 99.9\%), were prepared to obtain solutions of $100 \mathrm{mgl}^{-1}$ metal concentration. The adsorption studies were carried out during 7 and $24 \mathrm{~h}$, at pH5.0 and $25^{\circ} \mathrm{C}$ as a function of bark pulp density. The pulp density expressed in terms of grams of dry pine bark per volume of contaminated solution varied from 1 to $5 \mathrm{~g} \mathrm{I}^{-1}$. Each experiment was performed in $500 \mathrm{ml}$ of contaminated solution. Atomic absorption spectrophotometry (AAS, Perkin Elmer Model 2380) was performed to determine residual lead concentrations in solution after the sorption treatments. The amount of sorbed lead(II) was calculated as the difference between the initial total concentration of lead(II) used in the experiments and the residual concentration determined by AAS. Scanning electron microscopy (FEI Quanta 250 FEG SEM) was used to evaluate the composition of the bark charged with metal. Semi-quantitative elemental analysis was performed by EDX analysis of fluorescence intensities.

To examine the sorptive interactions between $\mathrm{Pb}$ and bark diffuse reflectance infrared Fourier transform spectroscopy (DRIFTS) and X-ray photoelectron spectroscopy (XPS) were applied. FT-IR spectroscopy experiments were carried out on a IFS 55 spectrometer (Bruker) using diffuse reflectance mode (Harrick Attachment). The detector was of a MCT type and cooled at liquid nitrogen temperature (77 K). XP spectra were recorded on a Kratos Axis Ultra instrument with a monochromatic Al $\mathrm{K}_{\alpha}$ source. The system has a hemispherical analyzer with a hybrid (electrostatic and magnetic) lens system, charge neutralization and a delay line detector (DLD). Samples were fixed on the sample holder using double-sided tape. The X-ray source was operated with a power of $180 \mathrm{~W}$ ( $15 \mathrm{kV}$ acceleration voltage and $12 \mathrm{~mA}$ emission current). The pressure in the analysis chamber was below $10^{-8} \mathrm{mbar}$ during data analysis. For high resolution scans of the photoemission from individual core levels the instrument operated in CAE (constant analysis energy) mode, with a pass energy of $20 \mathrm{eV}$. Low-resolution survey scans of the whole photoemission spectrum were obtained with a pass energy of $80 \mathrm{eV}$. All analytical experiments were carried out at least in duplicate, and the average results are presented.

\section{Results and discussion}

Figure 1 shows the kinetics of $\mathrm{Pb}$ (II) adsorption from $100 \mathrm{mg} \mathrm{Pb}$ (II)/I aqueous solution for different pulp densities at $\mathrm{pH} 5$. When pulp density increases from 1 to $5 \mathrm{gl}^{-1}$ the intermediate zone of adsorption observed for other metals (Montes et al, 2004) disappears. Surface saturation is quickly attained (after just $100 \mathrm{~min}$ ). This situation can only be observed in the case of copper at concentrations of three orders of magnitude higher. ${ }^{[17]}$ The latter shows a high affinity of lead to the substrate in comparison with copper for similar experimental conditions.

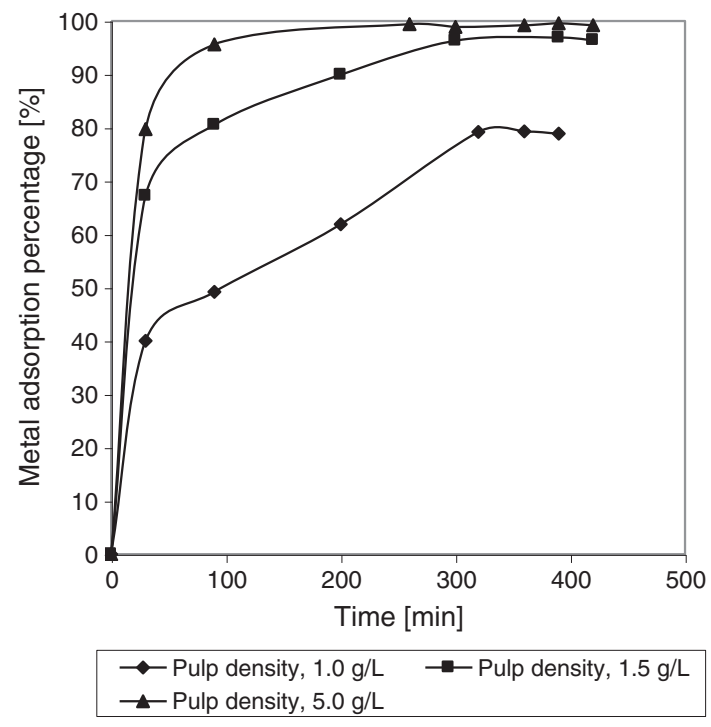

Figure 1. Adsorption of lead on activated pine bark. Initial concentration of $\mathrm{Pb}$ (II) $100 \mathrm{mgl}^{-1}, \mathrm{pH}$ 5.0.

At $\mathrm{pH} 5$ the aqueous solution contains lead in form of the ions $\mathrm{Pb}^{2+}$ and $\mathrm{Pb}(\mathrm{OH})^{+} .^{[18]}$ Lead can form bi- and monodentate complexes, with the hydroxo species also forming complex structures in solution. ${ }^{[19]}$

As one would expect, higher pulp densities are associated with more lead sorption (Fig. 1, Table 1) and removal of more lead from the solutions. A $24 \mathrm{~h}$ exposure removes more than $90 \%$ of lead for all three investigated pulp densities (Table 1). However, because lead removal is already highly efficient ( $96 \%$ after $7 \mathrm{~h}, 97.5 \%$ after $24 \mathrm{~h}$ ) at a pulp density of $1.5 \mathrm{gl}^{-1}$ the beneficial effect of adding more pulp is very limited. In fact, the sorption capacity (Table 1) at a pulp density of $5 \mathrm{gl}^{-1}$ is less than one third of the capacity at 1.5 and $1 \mathrm{gl}^{-1}$.

Furthermore, from a kinetic standpoint, Table 2 shows that at $5 \mathrm{gl}^{-1}$ pulp density the plateau is reached after $7 \mathrm{~h}$ time which is not related with the saturation state. At pulp densities of $1 \mathrm{gl}^{-1}$

Table 1. Adsorption capability of bark after exposure to $\mathrm{Pb}$ (II) ions for $7 \mathrm{~h}$ and $24 \mathrm{~h}$. Initial $\mathrm{Pb}$ (II) concentration: $100 \mathrm{mg} \mathrm{I}^{-1} ; \mathrm{pH}=5.0$

\begin{tabular}{|c|c|c|c|c|}
\hline \multirow{2}{*}{$\begin{array}{l}\text { Pulp density } \\
{\left[\mathrm{gl}^{-1}\right]}\end{array}$} & \multicolumn{2}{|c|}{$\begin{array}{c}\text { Sorption } \\
\text { [\%] }\end{array}$} & \multicolumn{2}{|c|}{$\begin{array}{l}\text { Sorption capacity } \\
\text { [mg/g dry bark] }\end{array}$} \\
\hline & $7 \mathrm{~h}$ & $24 \mathrm{~h}$ & $7 \mathrm{~h}$ & $24 \mathrm{~h}$ \\
\hline 1.0 & 78.8 & 93.7 & 78.8 & 93.7 \\
\hline 1.5 & 96.4 & 97.5 & 64.3 & 65.0 \\
\hline 5.0 & 99.2 & 99.7 & 19.8 & 19.9 \\
\hline
\end{tabular}

Table 2. Pseudo-second order rate constant $k_{2}$ and fit quality factor $\mathrm{R}^{2}$ for $\mathrm{Pb}$ (II) adsorption on pine bark at $\mathrm{pH} 5$

\begin{tabular}{lcc}
$\begin{array}{l}\text { Pulp density } \\
{\left[\mathrm{gl}^{-1}\right]}\end{array}$ & $\begin{array}{c}k_{2} \\
{\left[\mathrm{~min}^{-1} \mathrm{~mol}^{-1}\right]}\end{array}$ & $\mathrm{R}^{2}$ \\
1.0 & $1.0 \times 10^{-4}$ & 0.969 \\
1.5 & $8.0 \times 10^{-4}$ & 0.967 \\
\hline
\end{tabular}


and $1.5 \mathrm{gl}^{-1}$ adsorption follows approximately a pseudo-second order kinetics with respect to lead concentration (Eqn 1).

$$
-\frac{d}{d t}\left[P b^{2 \dagger}\right]=k_{2}\left[P b^{2+}\right]^{2}
$$

The experimentally observed rate constants for lead sorption at these pulp densities are on the order of $10^{-8} \mathrm{I} \mathrm{min}^{-1} \mathrm{~mol}^{-1}$ (Table 2), which is approximately one to two orders of magnitude higher than the value previously observed for copper ions under otherwise identical experimental conditions. ${ }^{[16]}$ At a pulp density of $5 \mathrm{~g} \mathrm{l}^{-1}$ the kinetics observed were too fast to reliably distinguish between first and second order kinetics.

Table 3 shows the results of the EDX elemental analysis of original washed bark and after the sulfuric acid treatment. The acid treatment reduces the concentrations of $\mathrm{K}, \mathrm{Mg}, \mathrm{Mn}$ and $\mathrm{Ca}$ significantly, while other metal concentrations ( $\mathrm{Na}, \mathrm{Al}, \mathrm{Si}, \mathrm{Ti}, \mathrm{Fe}$ and $\mathrm{Cu}$ ) remain almost constant. Acid hydrolysis of some regions takes place and is likely to lead to active regions for metal sorption (Montes et al, 2005; Montes-Atenas et al. 2014). In the following, all experiments are performed with activated bark.

Figure 2 shows images obtained by SEM analysis after sorption under conditions of the two low pulp densities. EDX elemental analysis at the spots marked in the figures revealed significant heterogeneity in the $\mathrm{Pb}$ distribution across the lignocellulosic grains. The $\mathrm{Pb} / \mathrm{O}$ weight ratio varied from 2:1 to 3:1 regardless the pulp density

\begin{tabular}{|lcc|}
\hline \multicolumn{3}{|c|}{$\begin{array}{l}\text { Table 3. Semi-quantitative EDX analysis of the elemental composition } \\
\text { of pine bark (reported values are in mg per g of dry bark) }\end{array}$} \\
\cline { 2 - 3 } Element & \multicolumn{2}{c|}{ Metal content [mg/g(bark)] } \\
\cline { 2 - 3 } & Washed bark & Activated bark \\
\hline $\mathrm{Na}$ & 0.98 & 0.94 \\
$\mathrm{~K}$ & 2.03 & 1.08 \\
$\mathrm{Mg}$ & 2.40 & 0.79 \\
$\mathrm{Ca}$ & 12.80 & 5.70 \\
$\mathrm{Al}$ & 6.40 & 7.00 \\
$\mathrm{Si}$ & 17.10 & 21.30 \\
$\mathrm{Ti}$ & 0.47 & 0.46 \\
$\mathrm{Mn}$ & 0.57 & 0.11 \\
$\mathrm{Fe}$ & 4.80 & 4.30 \\
$\mathrm{Cu}$ & 0.025 & 0.025 \\
\hline
\end{tabular}

value used in the experiments. Similar observations of varying metal content were previously seen for untreated bark. ${ }^{[17]}$

Figure 3 shows the DRIFTS analysis obtained for part of the finger print region. In the range from 3600 to $3000 \mathrm{~cm}^{-1}$ a broad band is observed, indicating the presence of $\mathrm{O}-\mathrm{H}$ and $\mathrm{C}-\mathrm{H}$ stretching vibrations. At wavenumbers ranging between 2000 and $1500 \mathrm{~cm}^{-1}$ there is a strong band at $1610 \mathrm{~cm}^{-1}$ representing the carbonyl $\mathrm{C}=\mathrm{O}$ stretch. When $\mathrm{Pb}$ is sorbed onto bark, a broadening of the band occurs. This effect is visible even at the lowest pulp densities. In agreement with observations, ${ }^{[2,20]}$ the band at wavenumbers of approximately $1512 \mathrm{~cm}^{-1}$, which is because of aromatic skeletal vibrations, is also slightly modified because of sorption.

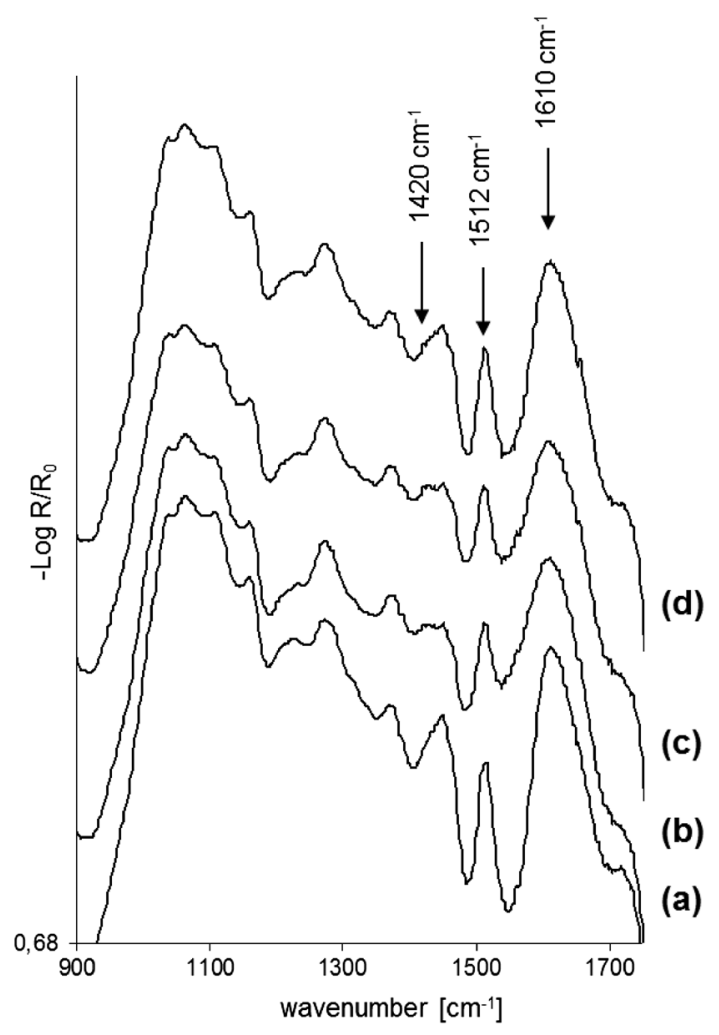

Figure 3. DRIFTS spectra for activated bark (a) and bark charged with solutions containing 1 (b), 1.5 (c) and 3 (d) $\mathrm{g} \mathrm{Pb}^{-1}$. Pulp density: $1.5 \mathrm{gl}^{-1}$.
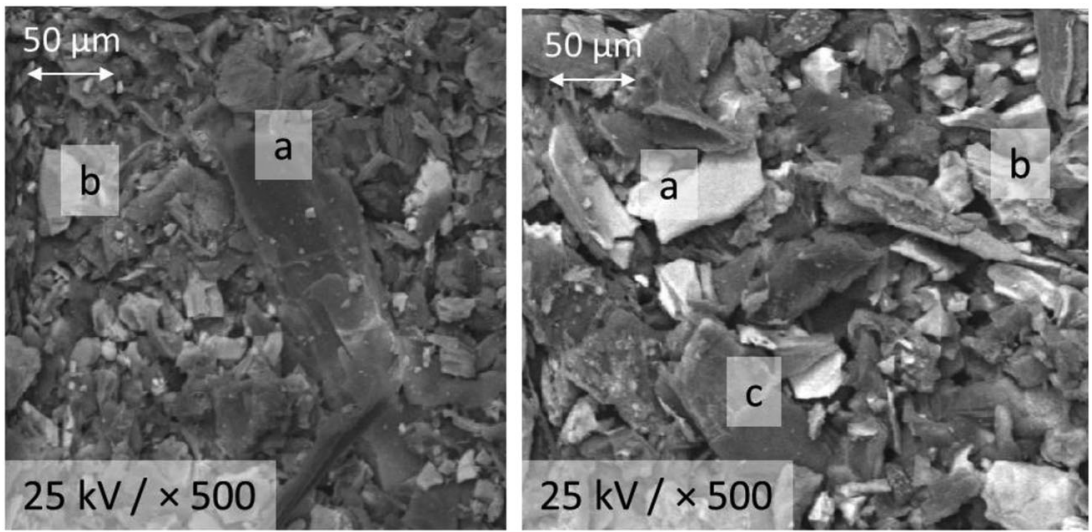

Figure 2. SEM images of activated pine bark loaded with adsorbed $\mathrm{Pb}(\mathrm{II})$. Left: Pulp density $1.0 \mathrm{gl}^{-1}$. EDX analysis indicates Pb/O weight ratios of 2:1 and 3:1 in spots a) and b), respectively. Right: Pulp density $1.5 \mathrm{gl}^{-1}$. EDX indicates $\mathrm{Pb} / \mathrm{O}$ weight ratios decreasing from a) to $\mathrm{c}$ ) ranging from approximately 2:1 to 3:1. 
Several scientific reports have been devoted only to analyze and to interpret the results from X-ray photoelectron spectra of wood and compounds derived from it. ${ }^{[21-24]}$ Figure 4 shows the $C 1 \mathrm{~s}$ and O1s emission lines obtained for the untreated sample of pine bark (sample 1) and charged with $\mathrm{Pb}$ (II) ions (sample 2). The energy scale was fixed and referred to $285 \mathrm{eV}$ (Fig. 4), in agreement with most studies reported [22, 24-26]. Past studies of wood and carbohydrates indicated that the $\mathrm{C} 1 \mathrm{~s}$ line should have a component arising from $\mathrm{C}-\mathrm{C}$ and $\mathrm{C}-\mathrm{H}$ bonds of adventitious carbon contamination at around $285 \mathrm{eV} .^{[25]}$ The C1s components visible in the spectra increasing in energy are because of $\mathrm{C}-\mathrm{C}$ and $\mathrm{C}-\mathrm{H}$ and $\mathrm{C}-\mathrm{O}$ groups, respectively. The full widths at half maximum (FWHMs) of these peaks (1.1-1.4 eV) are similar to those observed in previous studies. ${ }^{[26]}$

The $\mathrm{O} / \mathrm{C}$ ratio at the original bark material is 0.23 , which is somewhat lower than the value of 0.33 expected for lignin. ${ }^{[21]}$ The latter indicates the presence of significant cellulosic components. The observed value is in fact identical to that observed previously for the wood of Pinus Sylvestris. ${ }^{[23]}$ The ratio decreases by only $1-2 \%$ when $\mathrm{Pb}$ is sorbed onto the pine bark, which implies that $\mathrm{Pb}$ (II) does not significantly alter the carbon/oxygen ratio in the material. In fact, the overall $01 \mathrm{~s}$ emission and the overall $\mathrm{C} 1 \mathrm{~s}$ emission both decrease in intensity by about $23 \%$, suggesting that sorption at the surface of the bark is substantial (see discussion below). Strikingly, the FWHMs of $\mathrm{C} 1 \mathrm{~s}$ emission lines, $1.25 \mathrm{eV}$, reduce their values to around $1.06 \mathrm{eV}$ when $\mathrm{Pb}(\mathrm{II})$ is adsorbed. This may be related to preferential chemical interaction of $\mathrm{Pb}$ (II) with $\mathrm{C}-\mathrm{O}$ defect sites at the surface of bark substrates. The interaction with $\mathrm{Pb}$ could then cause a sharpening of the line by removal of spectral contributions from chemical metastable and reactive surface sites.

The 01 s line is strongly perturbed by $\mathrm{Pb}$ (II) adsorption. The peak at the lowest position shifts to lower binding energy values, confirming a reductive environment because of $\mathrm{Pb}$ (II) adsorption. The peak associated with $\mathrm{O}-\mathrm{C}-\mathrm{O}$ is similarly shifted towards lower binding energies but in smaller magnitude compared to that representing $\mathrm{C}-\mathrm{O}$ type structures. Additionally, the intensity of $\mathrm{C}-\mathrm{O}$ peak increases relative to the other peak. This suggests that not all sites present similar active sites. Most of them have $\mathrm{C}-\mathrm{O}$ sites for adsorption while the amount of phenolic sites varies locally through bark structure. The mechanism, therefore, should take place in well distributed $\mathrm{C}-\mathrm{O}$ groups and as a second type of sites in significance it would be the phenolic groups.
The 01s line has previously been less analyzed and few scientific articles have mentioned it. ${ }^{[21,22,25]}$ The two peaks at around 532.4 and $533.5 \mathrm{eV}$ have been assigned to $\mathrm{C}-\mathrm{O}$ (lignin and extractives) and $\mathrm{O}-\mathrm{C}-\mathrm{O}$, respectively. Previous assignments used to consider three bands, ${ }^{[25]}$ including $\mathrm{C}=\mathrm{O}$ species as well as oxygen atoms linked to cellulose structure and phenolic oxygens. Taking the lowest binding energy $01 \mathrm{~s}$ component as energy reference, the binding energy shift of the two others should be 1.6 and $2.7 \mathrm{eV}$, respectively. ${ }^{[25]}$ Our results differ from those values; this may indicate a significant difference in composition between the materials investigated. For our experiments, we can exclude charging of the sample in the X-ray beam, as the FWHM values in our spectra are close to $1.2 \mathrm{eV}$, which is significantly lower than in the previous work. XPS analysis of previous samples also showed that the addition of water to bark samples previously loaded with $\mathrm{Pb}$ (II) led to a water peak located at the lowest binding energy found. The series of results obtained show one main quite symmetrical peak at $532.7 \mathrm{eV}$ with standard deviation of $0.1 \mathrm{eV}$. This also explains the variability in its position because it is at the limit of the peak signal.

Figure 5 shows the $\mathrm{Pb}_{4 / 2}$ emission line (full survey spectra of $\mathrm{Pb}$ (II) loaded, and original pine bark is presented in the Supplementary data file). The position observed for $\mathrm{Pb}_{4} \mathrm{f}_{7 / 2}$ line indicates the presence of carboxylic bi-dentate sites. ${ }^{[27]}$ Neither sulfur nor nitrogen

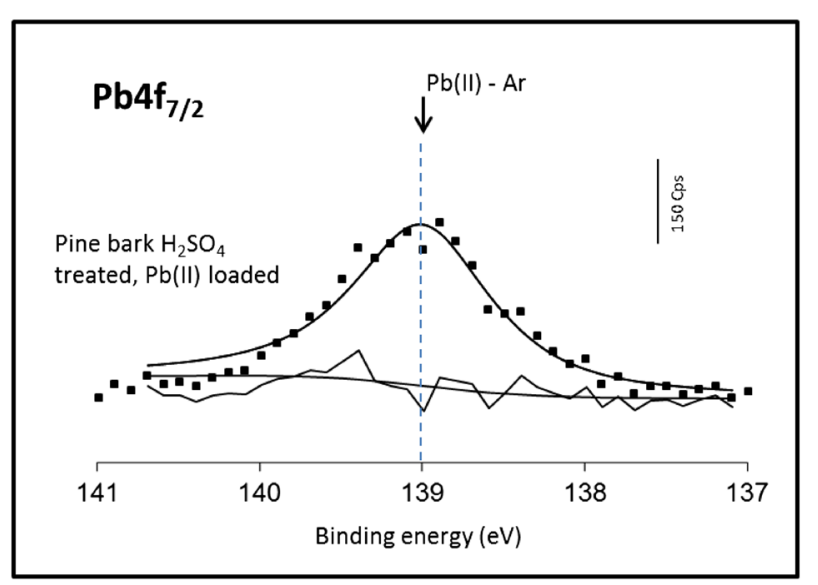

Figure 5. XPS analysis of pine bark sample charged with $\mathrm{Pb}$ (II). Conditions of adsorption: Batch experiments, $\mathrm{pH} 5.5,25^{\circ} \mathrm{C}, 5 \mathrm{~g} \mathrm{~Pb}(\mathrm{II}) \mathrm{I}^{-1}$.
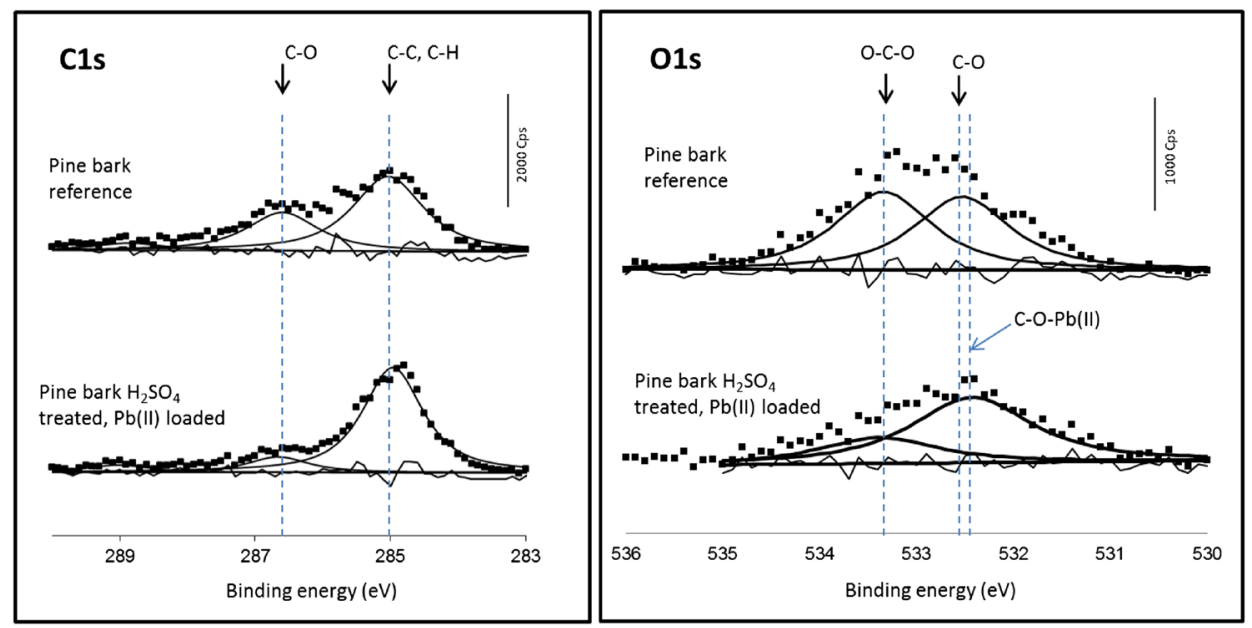

Figure 4. XPS spectra of pine bark samples. Sample 1: Original pine bark; sample 2 loaded for $24 \mathrm{~h}$ with $\mathrm{Pb}(\mathrm{II})$ in an acid aqueous solution ( $\mathrm{pH} 5$ ) at $5 \mathrm{~g} \mathrm{I}{ }^{-1}$ pulp density. 
was detected, so the presence of lead nitrate or sulfate could be excluded. Furthermore, lead oxide appears at lower binding energies (near to $137 \mathrm{eV}$ ); therefore, lead is not adsorbed in that form. ${ }^{[28]}$ Lead hydroxide presents a position slightly lower but close to that obtained. We therefore conclude that adsorption involves a mixture of hydroxyl and carboxylic groups linked to $\mathrm{Pb}$ (II) ions. The latter agrees with previous EXAFS studies that indicated the presence of $\mathrm{Pb}-\mathrm{O}$ bonds $^{[29]}$ after adsorption.

\section{Conclusions}

The present work studied the possible mechanisms taking place during the adsorption of $\mathrm{Pb}$ (II) onto Radiata pine bark. It was found that there is a high affinity of $\mathrm{Pb}$ (II) towards the pine bark substrate, obtaining loading capacities of almost $10 \%$ (93.7 mg Pb(II)/g dry bark). Mono-hydroxylated species and free lead ions were presented as the major responsible of adsorption. The SEM analysis showed that the heterogeneity of the adsorption will depend strongly on the scale of measurement. Nevertheless, the heterogeneity in composition was proved by using XPS analysis. DRIFTS analysis revealed that the adsorption mechanism is complex, mainly driven by bark surface sites involving $\mathrm{C}-\mathrm{O}$ groups. This was confirmed by XPS analysis revealing that the latter mentioned sites are the most active to accomplish $\mathrm{Pb}$ (II) adsorption. Phenolic and cellulose oxygen sites are also relevant in the mechanism but apparently the high heterogeneity of the bark surface just shows these types of sites in some specific regions and not widespread distributed as $\mathrm{C}-\mathrm{O}$ groups.

\section{Acknowledgements}

SLMS gratefully acknowledges financial support of the Bragg Centenary Chair by the Royal Academy Engineering, Infineum plc and DIAMOND Light Source Ltd. The XPS measurements were supported by EPSRC grant EP/D023807/1.

\section{References}

[1] Degremont, Memento Technique de l'Eau, ed. Lavoisier. Vol. 1: Technique Et Documentation. 594, 1989.

[2] I. Gaballah, G. Kilbertus, J. Geochem. Explor. 1998, 62, 241.

[3] S. Al-Asheh, F. Banat, D. Al-Rousan, Journal of Cleaner Production 2003, $11,321$.

[4] O. Altin, O. Ozbelge, T. Dogu, J. Colloid Interface Sci. 1998, 198, 130.

[5] S. E. Bailey, T. J. Olin, R. M. Bricka, D. D. Adrian, Water Res. 1999, 33, 2469.

[6] M. C. Basso, E. G. Cerrella, A. L. Cukierman, Industrial and Engineering Chemistry Research 2002, 41, 3580.

[7] X. Cao, L. Q. Ma, D. R. Rhue, C. S. Appel, Environ. Pollut. 2004, 131, 435.
[8] M. Cruz-Guzman, R. Celis, M. C. Hermosin, P. Leone, M. Negre, J. Cornejo, Soil Science Society of America Journal 2003, 67, 1378.

[9] Y. S. Ho, C. T. Huang, H. W. Huang, Process Biochem. 2002, 37, 1421.

[10] A. Jang, Y. Seo, P.L. Bishop, Environ. Pollut. 2005, 133, 117.

[11] V. C. Taty-Costodes, H. Fauduet, C. Porte, A. Delacroix, J. Hazard. Mater. 2003, B105, 121.

[12] J. Rubio, R. Cooper, Remocao de iones cobre por flotacao por ar dissolvido. in IV Encuentro del Hemisferio Sur sobre la Tecnologia Mineral, Concepcion. Chile, 1994.

[13] C. E. N. Oropeza, Intoxicación por Plomo: De la Detección a la Prevención Primaria, Indicadores y Noticias de Salud, Instituto Nacional de Salud Pública de México, 1995.

[14] R. J. Watts, Common Hazardous Wastes: Nomenclature, Industrial Uses and Disposal Histories, in Hazardous Wastes, Sources, Pathways and Receptors, I. John Wiley ans Sons, Editor, 1997, pp. 123-124.

[15] I. Gaballah, I. D. Goy, G. Kilbertus, J. Thauront, Decontamination of synthetic solutions containing lead ions using modified barks. in 123rd TMS Annual Meeting, TMS, San Francisco, California. USA., 1994.

[16] S. Montes, G. Montes-Atenas, F. Salomo, E. Valero, O. Diaz, Bull. Environ. Contam. Toxicol. 2006, 76, 171.

[17] S. Montes, G. Montes-Atenas, A. Vilches, Study of removing copper (II) and chromium (VI) from aqueous solution using bark pine. in TMS Fall 2002 Extraction and Processing Division Meeting, Lulea, Sweden, 2002.

[18] P. Huang, D.W. Fuerstenau, Colloids and Surfaces A: Physicohemical and Engineering Aspects 2001, 177, 147.

[19] F.A. Cotton, G. Wilkinson, Advanced Inorganic Chemistry, ed. I. John Wiley ans Sons., New York, Chichester, Brisbane, Toronto, Singapore: Wiley-Interscience Publication, 1988.

[20] G. Vasquez, J. Freire, J. Gonzalez, G. Antorrena, Holz Als Roh-und Werkstoff 2000, $58,57$.

[21] P. Nzokou, D.P. Kamdem, Surf. Interface Anal. 2005, 37, 689.

[22] A. Shchukarev, B. Sundberg, E. Mellerowicz, P. Persson, Surface and Interface Analysis 34, 2002, pp. 284.

[23] Q. Shen, P. Mikkola, J.B. Rosenholm, Colloids Surf. A Physicochem. Eng. Asp. 1998, 145, 235.

[24] G. Sinn, A. Reiterer, S.E. Stanzl-Tschegg, J. Mater. Sci. 2001, 36, 4673.

[25] W. T. Y. Tze, G. Berhardt, D. J. Gardner, A. W. Christiansen, International Journal of Adhesion and Adhesives 2006, 26, 550.

[26] L.-S. Johansson, J. M. Campbell, P. Fardim, A. H. Hulten, J.-P. Boisvert, M. Ernstsson, Surf. Sci. 2005, 584, 126.

[27] P. A. Bertrand, P. D. Fleischauer, Journal of Vacuum Science Technology 1980, 17, 1309.

[28] C. D. Wagner, A. V. Naumkin, A. Kraut-Vass, J. W. Allison, C. J. Powell, J. R. Rumble, NIST Standard Reference Database 20, Version 3.4 (Web Version), Measurement Services Division of the National Institute of Standards and Technology (NIST), 2006.

[29] M. Marmiroli, G. Antonioli, E. Maestri, N. Marmiroli, Environ. Pollut. 2005, 134, 217.

\section{Supporting information}

Additional supporting information may be found in the online version of this article at the publisher's web-site. 